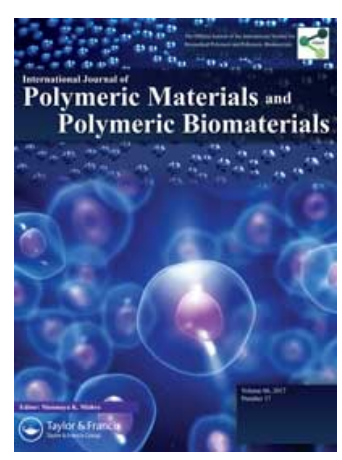

International Journal of Polymeric Materials and Polymeric Biomaterials

ISSN: 0091-4037 (Print) 1563-535X (Online) Journal homepage: https://www.tandfonline.com/loi/gpom20

\title{
Natural rubber latex: Development and in vitro characterization of a future transdermal patch for enuresis treatment
}

Natan Roberto de Barros, Matheus Carlos Romeiro Miranda, Felipe Azevedo Borges, José Lúcio Pádua Gemeinder, Ricardo José de Mendonça, Eduardo Maffud Cilli \& Rondinelli Donizetti Herculano

To cite this article: Natan Roberto de Barros, Matheus Carlos Romeiro Miranda, Felipe Azevedo Borges, José Lúcio Pádua Gemeinder, Ricardo José de Mendonça, Eduardo Maffud Cilli \& Rondinelli Donizetti Herculano (2017) Natural rubber latex: Development and in vitro characterization of a future transdermal patch for enuresis treatment, International Journal of Polymeric Materials and Polymeric Biomaterials, 66:17, 871-876, DOI:

10.1080/00914037.2017.1280795

To link to this article: https://doi.org/10.1080/00914037.2017.1280795

Accepted author version posted online: 08

Feb 2017.

Published online: 28 Aug 2017.

Submit your article to this journal $₫$

Џll Article views: 125

View Crossmark data ¿

Citing articles: 9 View citing articles 지 


\title{
Natural rubber latex: Development and in vitro characterization of a future transdermal patch for enuresis treatment
}

\author{
Natan Roberto de Barros ${ }^{\mathrm{a}}$ (D), Matheus Carlos Romeiro Miranda ${ }^{\mathrm{a}}$, Felipe Azevedo Borges ${ }^{\mathrm{a}}$, José Lúcio Pádua \\ Gemeinder $^{\mathrm{b}}$, Ricardo José de Mendonçac ${ }^{\mathrm{c}}$, Eduardo Maffud Cilli ${ }^{\mathrm{a}}$ (D) and Rondinelli Donizetti Herculano ${ }^{\mathrm{b}}$
}

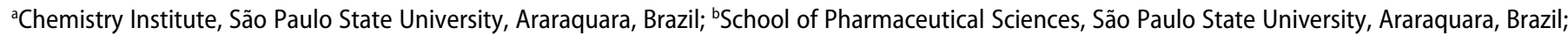
'Biochemistry Section, UFTM—ICBN, Uberaba, Brazil

\begin{abstract}
Enuresis affects up to $20 \%$ of children of 5 years old, enuretic children present arginine vasopressin secretion deficiency, compared to normal children. To keep the level of antidiuretic hormone in the body, the aim of this work was to develop natural rubber latex membranes loaded with desmopressin peptide and characterize its in vitro release. Results demonstrated that $60 \%$ of desmopressin incorporated in natural latex was released up to $96 \mathrm{~h}$. Furthermore, hemolysis tests showed no detectable disturbance of the red blood cell membranes. Based on the results, it was possible to conclude that natural latex membranes are able to load desmopressin.
\end{abstract}

\section{GRAPHICAL ABSTRACT}

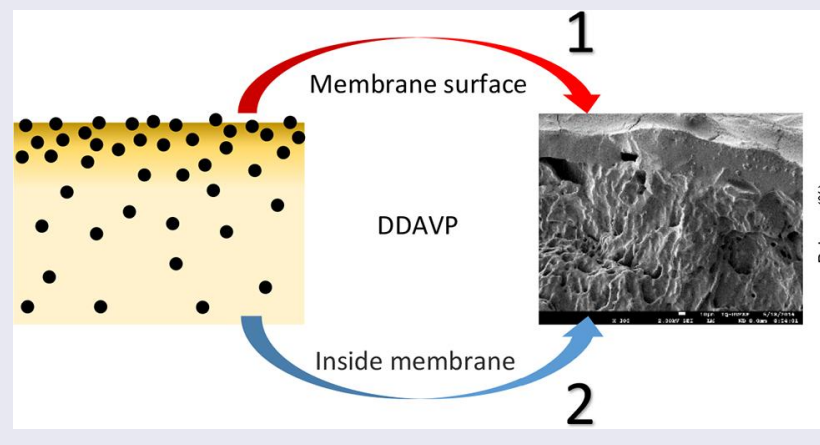

\section{ARTICLE HISTORY}

Received 14 October 2016

Accepted 8 January 2017

\section{KEYWORDS}

Biomaterial; desmopressin; enuresis; natural rubber latex; sustained release

\section{Introduction}

Enuresis is defined as the repeated voiding of urine into the bed or clothes at least twice per week for at least 3 consecutive months in a child who is at least 5 years of age [1]. This common psychosomatic symptom affects $20 \%$ of children (of all 7 years old) and $2 \%$ of all adolescents that wet the bed at night [2]. The most enuretic children have a disease resolution spontaneously, with or without therapy. Unfortunately, not only the children but also their parents can have psychological and emotional problems, and due to these problems, enuresis must be treated.

The usual therapies for enuresis are psych and hypnotherapy, motivational therapy, bladder training, pharmacological manipulation, and alarm systems. These therapies are usually used together. The pharmacological options on enuresis treatment are anticholinergic, antidepressant, and antidiuretics. The drug usually prescribed for enuresis treatment is the antidepressant imipramine, however, imipramine shows serious side effects in overdosage cases, such as convulsions, cardiac problems, and coma. The risks of having a medication with potentially fatal side effects at home for a self-limited benign condition make the risk/benefit ratio poor [3].

Moreover, enuretic children have an arginine vasopressin (AVP) secretion deficiency, an antidiuretic peptide, compared to normal children [4]. Thus, to cure the AVP deficiency, desmopressin acetate (1-desamino-8-D-AVP [DDAVP]) can be used, a synthetic peptide AVP analogs (Figure 1).

Thus, the drug delivery system (DDS) is an interesting model to keep the level of antidiuretic hormone in the body. DDS offers many advantages such as reduced side effects, less frequent administration to produce the desired constant plasma concentration associated with improved patient compliance, elimination of the first-pass effect, sustained drug delivery, and interruption of treatment when necessary. There are carrier systems such as liposomes, niosomes, aquasomes, transfersomes, nanocapsules, microcapsules, cyclodextrins, microsponges, polymers, among others. The nature and 
<smiles>N=C(N)NCCCC(NC(=O)C1CCCN1C(=O)C(CSSCCC(=O)NC(Cc1ccc(O)cc1)C(=O)NCC(N)=O)NC(=O)C(CC(N)=O)NC(=O)C(CCC(N)=O)NC(=O)C(Cc1ccccc1)NC(=O)C(Cc1ccccc1)NC(=O)CNC(=N)N)C(=O)NCC(N)=O</smiles>

Figure 1. DDAVP peptide structure.

composition of carriers are varied, its administration is safe and convenient to the patient [5].

Barros et al. [6] developed a novel sustained released system containing oxytocin peptide in natural rubber latex (NRL) membranes, which can be used to stimulate the release of breast milk in humans and animals.

The NRL is extracted from rubber tree Hevea brasiliensis, it consists of a mixing colloidal rubber particles stabilized by a thin layer of phospholipids and proteins [7]. This biomaterial is an important inductor of the healing process of wounds, being used in several medical applications like prosthetics and bone grafts, with high mechanical resistance.

Mrué et al. [8] showed that latex membranes as prosthesis accelerated the tissue regeneration of a cervical esophagus segment in dogs. Ereno et al. [9] used NRL membranes in bone fractures, avoiding the epithelial tissue migration and facilitating regenerative bone cells' migration. Moreover, Araujo et al. [10] demonstrated that the NRL membrane has satisfactory interaction with tissues of the human tympanic membrane and good biocompatibility, with no signs of toxicity or allergic manifestations.

Considering this, researchers have been developing biomaterials based on NRL membranes as template for controlled release systems, showing promising results for future biomedical application. As an example, Phaechamud et al. [11] demonstrated that gentamicin was released from latex membranes up to 7 days, with good antimicrobial activities against Staphylococcus aureus and Pseudomonas aeruginosa. Furthermore, Aielo et al. [12] showed that the release time of sodium diclofenac using NRL membranes in vitro assay was increased from the typical $2-3 \mathrm{~h}$ for oral tablets to $74 \mathrm{~h}$. Moreover, Pichayakorn et al. [13] conducted a study of NRL matrix for nicotine controlled release, showing that the NRL is able to release nicotine up to $24 \mathrm{~h}$.

Finally, the aim of this work was to develop NRL membranes loaded with DDAVP peptide and characterize its in vitro release. The idea is, in the future, to obtain a transdermal patch for enuresis therapy that, when exposed to the skin, reacts releasing the peptide.

\section{Experimental}

\subsection{Natural rubber latex}

The NRL used in this study was commercial high ammonia from BDF Rubber Latex Co. Ltd. (producer and distributor of concentrated rubber latex, Guarantã, Brazil) of about $60 \%$ dry rubber content, $4-5 \%$ weight of nonrubber constituents such as proteins, lipids, carbohydrates, and 35\% of water. This NRL was obtained mixing two clones: RRIM 600 and PB 235 (Lot: 01703/13). After extraction, ammonia was used to keep the latex liquid $(\mathrm{pH}=10.20)$. The NRL protein content reduction was performed by centrifugation at $8,000 \mathrm{~g}$. The centrifugation method used does not eliminate all proteins present in NRL, only high-molecular weight proteins responsible for allergic and cytotoxic reactions obtaining the NRL biomedical (NRLb) $[14,15]$. The cream fraction after centrifugation was redispersed to make the desired $60 \%$ of dry rubber content latex and then washed twice by centrifugation to reduce the protein content on the solution.

\subsection{Membrane preparation}

NRLb membranes with DDAVP were obtained from method described by Miranda [16] and Barros et al. [6]. The preparation of membrane consisted of depositing $1.0 \mathrm{~mL}$ of $\mathrm{NRLb}\left(4^{\circ} \mathrm{C}\right)$ and $1.0 \mathrm{~mL}$ of DDAVP solution in ultrapure water $\left(1 \mathrm{mg} \mathrm{mL}^{-1}\right)\left(4^{\circ} \mathrm{C}\right)$ in circular plates $(\varnothing 22.30 \mathrm{~mm})$ and immediately (less than $2 \mathrm{~min}$ ) frozen using liquid nitrogen and then lyophilized. Figure 2 shows a step by step process from NRL extraction to DDAVP release.

\subsection{Fourier transform infrared}

Fourier transform infrared (FTIR) was used to identify functional groups (amines, amides, aromatic rings, alcohol, phenols, between others), besides providing the study by possible interactions between NRLb and DDAVP. Infrared spectra of samples were taken in the attenuated total

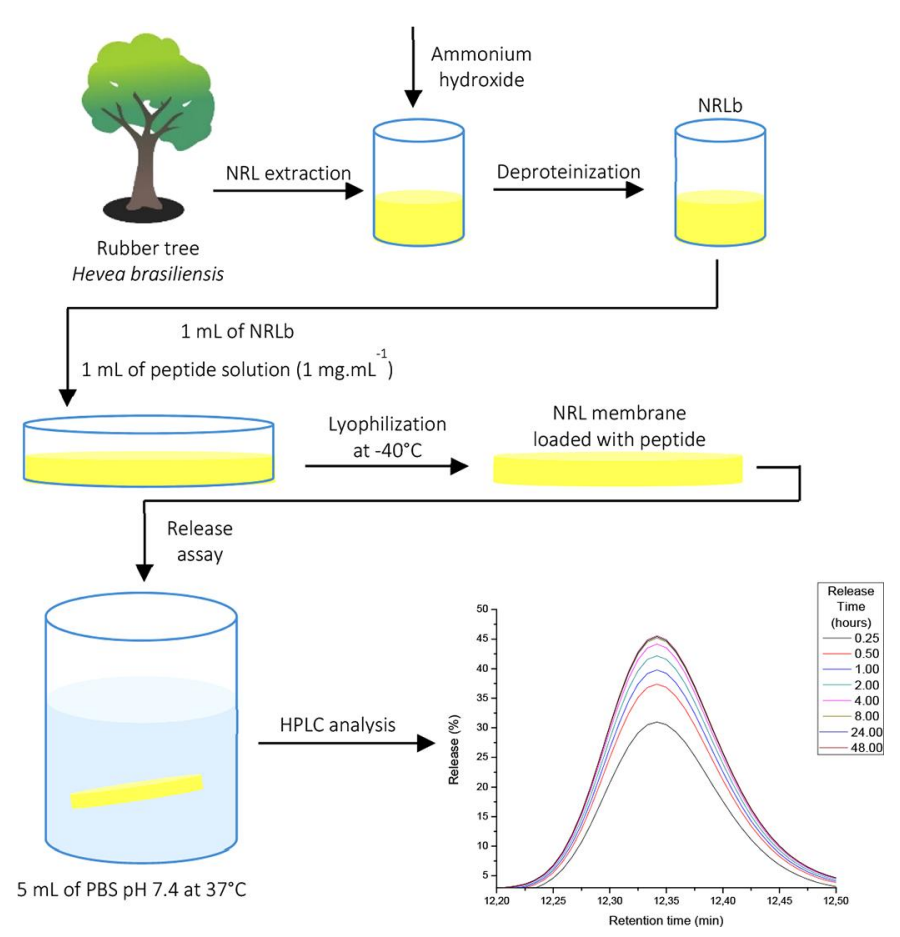

Figure 2. Step by step from NRL extraction, membrane production and DDAVP release. 
reflectance (ATR) method on region between 4000 and $400 \mathrm{~cm}^{-1}$ (resolution: $4 \mathrm{~cm}^{-1}$; scans: 32 ) using an FTIR spectrometer-Tensor 27/BRUKER (Billerica, MA).

\subsection{Water vapor transmission test}

Water vapor permeation of NRLb and NRLb-DDAVP membranes was determined gravimetrically in triplicate according to the method proposed by Akhgari et al. [17] with few modifications. The permeability cups were $1.5 \mathrm{~cm}$ in diameter. The Cups were filled with $15 \mathrm{~mL}$ of distilled water, in the cups the relative humidity (RH) was $100 \%$. Circular pieces of samples were placed on the cups and then placed in a desiccator containing phosphorus pentoxide $\left(\mathrm{P}_{2} \mathrm{O}_{5}\right)$ as a desiccant and filled with silica gel $(0 \% \mathrm{RH})$. At specific intervals, the cups were weighed and the profile of mass change was plotted versus time. Water vapor transmission (WVT) was calculated using Eq. 1:

$$
\mathrm{WVT}=\frac{w x}{t A P o(\mathrm{RH} 1-\mathrm{RH} 2)}
$$

where $w / t$ is the mass change (flux, $\mathrm{g} / \mathrm{h}$ ) resulted from slope of profile of the mass change versus time, $x$ is the film thickness $(\mathrm{mm}), A$ is the area of film surface exposed to the permeant $\left(\mathrm{m}^{2}\right), P o$ is the vapor pressure of pure water $\left(\right.$ at $25^{\circ} \mathrm{C}=3.159$ $\mathrm{kPa})$, and $(\mathrm{RH} 1-\mathrm{RH} 2)$ is the relative humidity gradient.

\subsection{Scanning electron microscopy}

Membrane surface and cross-sectional morphologies were examined at $300 \times$ and $1000 \times$ magnifications using highresolution scanning electron microscope (FEG-SEM; JEOL model $7500 \mathrm{~F}$, Akishima, Tokyo, Japan) with $2 \mathrm{KV}$, take-off angle of $35^{\circ}$, and gold as conductor material. Three aleatory areas were analyzed to perform the analysis.

\subsection{Release assay}

Since one of the objectives of the present study was to evaluate the DDAVP incorporation and release by NRLb membranes aiming at the development of a transdermal patch, the release evaluation method used was the multidirectional method, aiming the identification of DDAVP release or retention in the NRLb membrane. The release assays were performed in glass tubes with $5.0 \mathrm{~mL}$ phosphate buffer of $\mathrm{pH} 7.4$ at $37^{\circ} \mathrm{C}$. Aliquots were analyzed in a high performance liquid chromatography (HPLC) (Shimadzu model LC-10A/C-47A, Japan) in analytic mode, following these chromatography conditions: Solvent A $[0.045 \%$ trifluoroacetic acid (TFA) in $\left.\mathrm{H}_{2} \mathrm{O}\right]$ and $\mathrm{B}[0.036 \%$ TFA in acetonitrile $(\mathrm{ACN})]$ in a gradient of $5-95 \%(\mathrm{v} / \mathrm{v}) \mathrm{B}$ solvent in $30 \mathrm{~min}$, at a flow rate of $1 \mathrm{~mL} \mathrm{~min}^{-1}$ in a C18 KROMASIL$15.0 \times 0.46 \mathrm{~cm}$ column and UV detection at $220 \mathrm{~nm}$.

\subsection{Hemolytic activity}

The hemolytic activity of NRLb, DDAVP, and NRLb-DDAVP membranes was investigated according to Onuma et al. [18] using a 5\% defibrinated sheep blood suspension from NewProv Bioscience, lot: $16324 \mathrm{M}$, Brazil. The samples were extracted according to ISO $10993-12: 2006$, the extractions were performed in PBS ( $\mathrm{pH} 7.4$ ) at $37^{\circ} \mathrm{C}$ for $24 \mathrm{~h}$ and the extraction ratio was $200 \mathrm{mg} \mathrm{mL}^{-1}$. Serial dilutions of samples' extract were used to determine the percentage of hemolysis. The final volume in each well was $200 \mu \mathrm{L}$. Then $200 \mu \mathrm{L}$ of $1 \%(\mathrm{v} / \mathrm{v})$ suspension of erythrocyte (EA) was added to each well. The complement-free buffer in wells was used as standard with a zero degree of hemolysis (0\%), to attain $100 \%$ hemolysis; and $200 \mu \mathrm{L}$ of Triton X-100 1\% (v/v) was used instead of the buffer. The plate was incubated at $37^{\circ} \mathrm{C}$ for $1 \mathrm{~h}$ in Shaker Incubator (Quimis, Brazil) and then absorbance at $540 \mathrm{~nm}$ was determined in each well in an Epoch Microplate Spectrophotometer (BioTek, USA). Less than 5\% hemolysis was regarded as nontoxic effect level in the experiments [19]. The experiments were performed in triplicate and the hemolysis percentage was calculated using Eq. 2:

$$
\% \text { Hemolysis }=100 \times \frac{\text { Asample }- \text { Ablank }}{\text { Atriton }- \text { Ablank }}
$$

\section{Results and discussion}

\subsection{Fourier transform infrared}

The FTIR spectra of NRLb, DDAVP, and NRLb-DDAVP are represented in Figure 3. FTIR spectrum from NRLb membrane shows the characteristic absorptions for poly(cis-1,4isoprene): 2960 and $1375 \mathrm{~cm}^{-1} \mathrm{CH}_{3}$ strain; 2916, 2852, and $1446 \mathrm{~cm}^{-1} \mathrm{CH}_{2}$ strain; $1661 \mathrm{~cm}^{-1} \mathrm{C}-\mathrm{C}$ strain and $836 \mathrm{~cm}^{-1}$ $\mathrm{CH}$ off-plan. This last absorption is the most important to

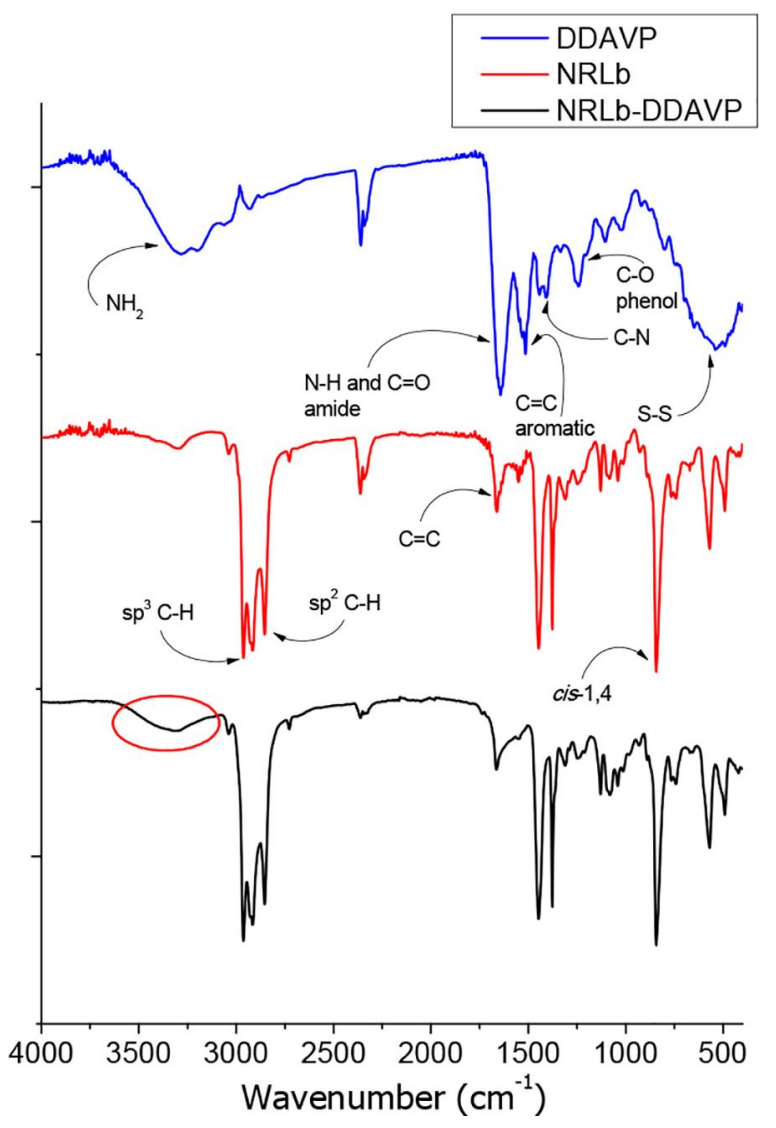

Figure 3. Comparative FTIR spectra from DDAVP, NRLb, and NRLb-DDAVP. 


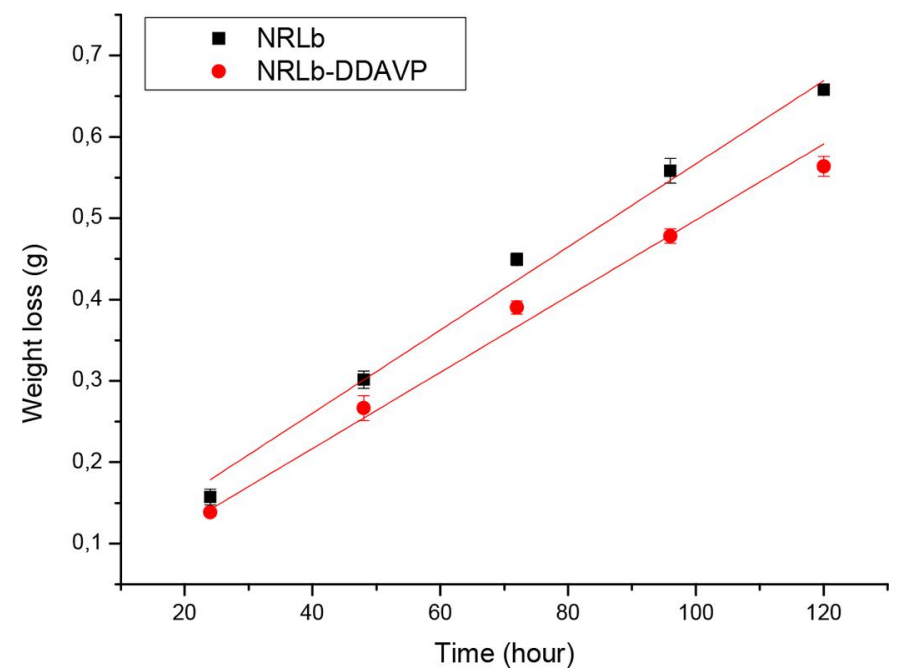

Figure 4. WVT for NRLb and NRLb-DDAVP.

identify NRL since this band is characteristic from $\mathrm{R}_{2} \mathrm{C}=\mathrm{CHR}$ (cis-1,4) function.

FTIR spectrum from DDAVP shows characteristic absorptions for peptides: $3280-3267 \mathrm{~cm}^{-1}$ for $\mathrm{NH}_{2}$ strain; $1643-1638 \mathrm{~cm}^{-1}$ for amine $\mathrm{NH}$ and amides $\mathrm{C}=\mathrm{O}$ strain; $1524-1514 \mathrm{~cm}^{-1}$ for aromatic $\mathrm{C}=\mathrm{C}$ strain; $1410-1403 \mathrm{~cm}^{-1}$

Table 1. WVT for NRLb and NRLb-DDAVP.

\begin{tabular}{lcc}
\hline Water vapor transmission & & \\
\hline Membrane & $w / t(\mathrm{~g} / \mathrm{h})$ & WVT $\left(\mathrm{g} \mathrm{mm} / \mathrm{m}^{2} \mathrm{~h} \mathrm{KPa}\right)$ \\
\hline NRLb & 0.00511 & 0.00688 \\
NRLb-DDAVP & 0.00468 & 0.00629 \\
\hline
\end{tabular}

w, WVT flux $(\mathrm{g} / \mathrm{h})$; WVT, water vapor transmission.
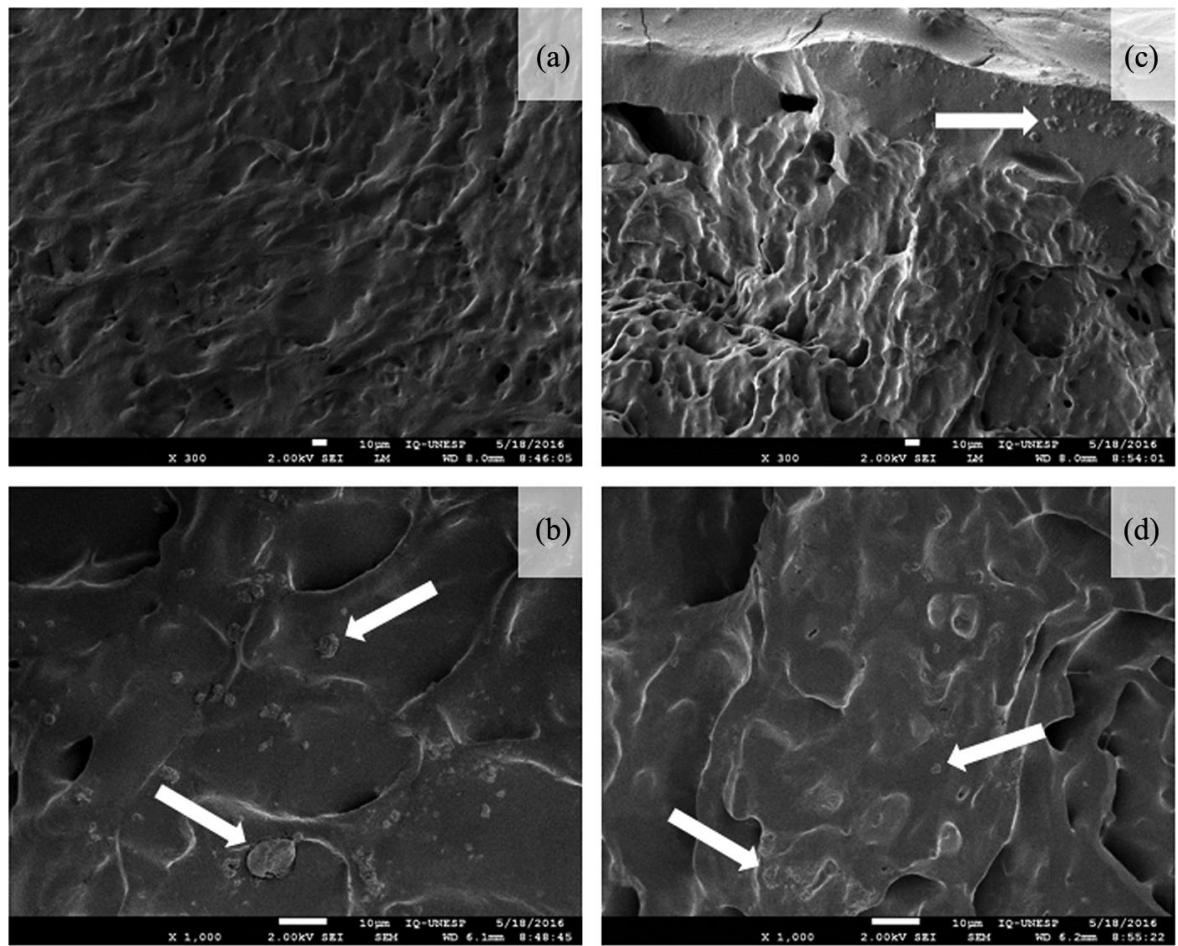

for amines and amides C-N strain; $1260-1242 \mathrm{~cm}^{-1}$ for phenol $\mathrm{C}-\mathrm{O}$ and/or aromatic C-N strain (can occur and overlap); $542-498 \mathrm{~cm}^{-1}$ for S-S strain.

Furthermore, the FTIR spectra comparison between NRLb, DDAVP, and NRLb-DDAVP showed that there is noncovalent interactions between DDAVP and NRLb (not showed additional absorption bands). Moreover, the characteristic bands of DDAVP were also observed in NRLb-DDAVP. This finding indicates that NRLb can retain DDAVP therein and posteriorly release it. Moreover, by the fact of NRLb be a natural rubber substrate, it has some proteins in its composition [20,21]. Thus, NRLb FTIR spectra exhibit characteristic absorption bands for peptides, such as DDAVP.

\subsection{WVT test}

Figure 4 shows that the rate of water vapor permeation was constant for NRLb membranes according to the linear equation $y=0.05594+0.00511 x$ ( $R$-square: 0.988$)$. This linear relation between amount of vapor permeated and time was also observed for NRLb-DDAVP $y=0.02973+0.00469 x$ (R-square: 0.991). However, the rate of water permeation $(w)$ for NRLb-DDAVP membranes was $8.58 \%$ smaller than NRLb. Table 1 lists the results of WVT experiments.

\subsection{Scanning electron microscopy}

The SEM images obtained are consistent with results obtained by Miranda [16], where the membranes produced by lyophilization technique presented a higher porosity when compared to those produced at room temperature. Membranes with

Figure 5. SEM of NRLb-DDAVP: (a) membrane surface at $300 \times$; (b) membrane surface at $1000 \times$; (c) membrane cross section at $300 \times$; (d) membrane cross section at $1000 \times$. 
Table 2. Values for the constants obtained from the biexponential function applied to the DDAVP release.

\begin{tabular}{lccc}
\hline Equation & \multicolumn{3}{c}{$y=A_{1}{ }^{*} \exp \left(-x / t_{1}\right)+A_{2}{ }^{*} \exp \left(-x / t_{2}\right)+y_{0}$} \\
\hline DDAVP & Adj. $R$-square: & 0.99824 & \\
& & Value & Standard error \\
& $y_{0}$ & 60.81089 & 0.4781 \\
$A_{1}$ & -24.63822 & 0.63392 \\
$t_{1}$ & 33.78412 & 2.77164 \\
$A_{2}$ & -19.80802 & 1.17589 \\
$t_{2}$ & 0.78962 & 0.1039 \\
\hline
\end{tabular}

larger pore density provide higher release of compound incorporated into matrix, increasing delivery system efficiency [22].

SEM images (with magnitude of $300 \times$ and $1000 \times$ ) from NRLb-DDAVP membrane surface are displayed in Figures $5 \mathrm{a}$ and 5b; in Figure 5b, the presence of DDAVP crystallization in surface can be observed. In addition, Figure $5 \mathrm{c}$ showed a greater DDAVP density crystallized near the surface, as can be observed in $300 \times$ magnitude.

\subsection{Release assay}

DDAVP release kinetics revealed one bi-exponential function: $y(t)=y_{0}+A_{1} e^{-t / \tau 1}+A_{2} e^{-t / \tau 2}$ where $y(t)$ is the DDAVP amount released by NRLb on time function $(t), y_{0}$ is the initial DDAVP amount in NRLb. The values for $A_{1}$ and $A_{2}$ (constants) and characteristic times $\tau 1$ and $\tau 2$ are listed in Table 2.

DDAVP release showed two-step kinetics (Figure 6): (i) burst release, releasing 35\% of incorporated DDAVP up to $2 \mathrm{~h}$, this step is in accordance with the SEM images, that shown a DDAVP responsible for the burst release portion on NRLb surface, followed by (ii) stable profile, from $35 \%$ at $2 \mathrm{~h}$ to $60 \%$ at $96 \mathrm{~h}$, due to DDAVP amount inside NRLb.

The release profile showed that $60 \%$ of DDAVP incorporated by NRLb membranes was released up to $96 \mathrm{~h}$ in $5 \mathrm{~mL}$ of PBS solution ( $\mathrm{pH}=7.4)$.

Semiempirical mathematical models were applied to evaluate that which are the physical parameters involving in DDAVP release by NRLb membranes. The better correlation coefficient $R^{2}(0.98)$ found for DDAVP kinetic release showed that the peptide released by NRLb membranes follows the Korsmeyer-Peppas mathematical model $\left(f(t)=k t^{n}\right)$, where is the fractional release of DDAVP at elapsed time $t, n$ $\left(1.44 \times 10^{-1}\right)$ is the release exponent (witch suggest the mechanism of release), and $k\left(30.6 \mathrm{~h}^{-n}\right)$ is the kinect constant (related to the structural and geometrical characteristics of the carrier) [23]. This model is applied to polymeric formulations when the release mechanism is unknown or can involve more than one mechanism such as polymeric matrix degradation, diffusion by pore density, expansion/dilatation between polymer chains, and erosion [24]. $n \leq 0.5$ indicates Fick diffusion (also known as "Higuchi equation"); $0.5 \leq n \leq 1.0$ indicates anomalous transport mechanisms; $n=1$ indicates case II transport (also known as "zero order equation", due to relaxation, swelling, and polymer erosion); and $n>1$ indicates super case II transport [25]. For DDAVP peptide, the value $n<0.5$ indicates that the release follows Fickian diffusion mechanism.

\subsection{Hemolytic activity}

The interactions between NRLb, DDAVP, and NRLb-DDAVP have also been studied by hemolysis experiments. Thereby, the hemolysis assay was performed to evaluate the cytolytic activity from the materials used. The release of hemoglobin was used to quantify the membrane-damaging properties of the materials. As $100 \%$ and $0 \%$ values used, Triton X-100 and phosphate buffer-treated EA, respectively (Figure 7).

Under these conditions, NRLb, DDAVP, and NRLb-DDAVP extracts showed no hemolytic effects up to $200 \mathrm{mg} \mathrm{mL}^{-1}$ (Figure 7) indicating no detectable disturbance of the red blood cell membranes. These results are similar for both Borges et al. [26] using coating the calcium phosphate $(\mathrm{Ca} / \mathrm{P})$ and Barros et al. [6] using oxytocin peptide in NRLb membranes. The test was realized according to the international standard ISO 10993-4:2006, showing that the membrane NRLb-DDAVP has no cytolytic activity.

This study proposed the DDAVP transdermal administration using NRLb membranes as an alternative to hypodermic injection, sublingual tablet, or nasal spray. However, this

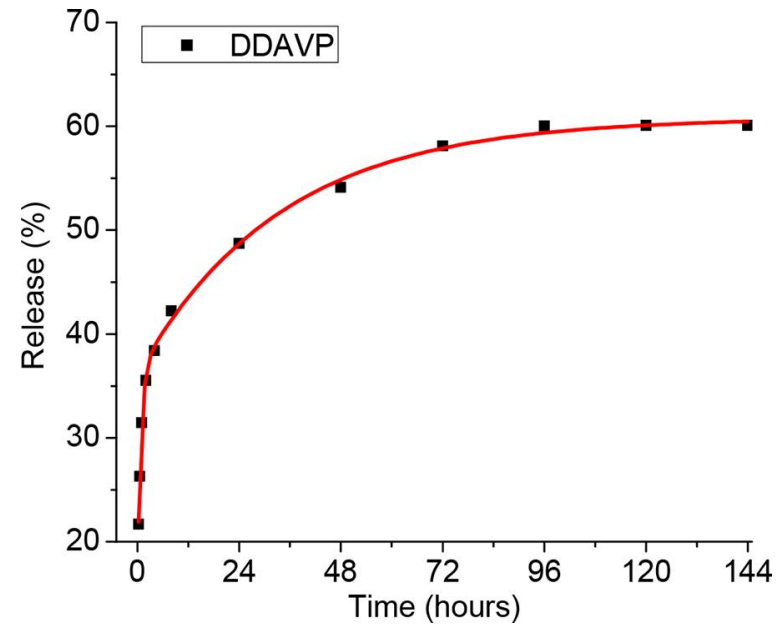

Figure 6. DDAVP release kinetics by NRL membranes.

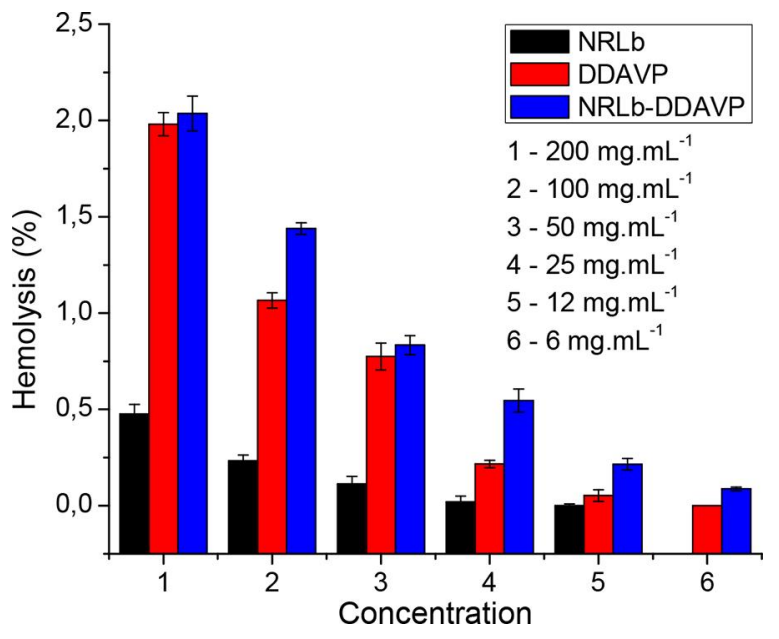

Figure 7. Hemolysis activity as a function of material concentrations. 

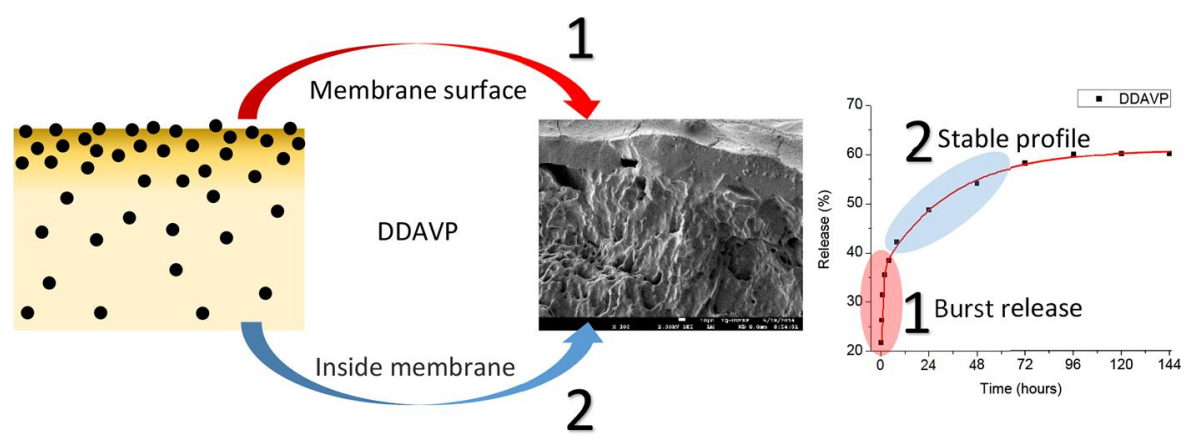

Figure 8. NRLb transdermal patch release scheme.

material must be subject to in vitro cutaneous permeation tests before its in vivo evaluation.

In summary, the relation between the SEM images and the release kinetic tests is shown clearly in Figure 8, displaying a greater DDAVP amount on the membrane surface, it is responsible for the burst release. In addition, the stable profile is consistent with the DDAVP inside NRLb membrane.

\section{Conclusion}

In conclusion, FTIR analysis showed that the NRLb matrix did not interact chemically with the DDAVP, retaining it in its polymeric network. NRLb-DDAVP membranes released at $96 \mathrm{~h}$, up to $60 \%$ of all incorporated peptide. The SEM images showed that a portion of DDAVP remains on the matrix surface, this portion being the responsible for burst release. On the other hand, another portion of DDAVP remains within the matrix, being this portion responsible for the stable profile release process. Moreover, the materials (DDAVP, NRLb and NRLb-DDAVP) presented no cell damaging effects up to $200 \mathrm{mg} \mathrm{mL}^{-1}$, where the hemolysis level was less than $5 \%$. Based on these results, it was possible to conclude that NRLb membranes are able to load DDAVP. The idea is, in the future, obtaining a transdermal patch for enuresis therapy.

\section{ORCID}

Natan Roberto de Barros (D) http://orcid.org/0000-0001-8689-4110 Eduardo Maffud Cilli (iD http://orcid.org/0000-0002-4767-0904

\section{References}

[1] Eiberg, H.; Berendt, I.; Mohr, J. Nat Genet. 1995, 10, 354.

[2] Caldwell, P. H. Y.; Sureshkumar, P.; Wong, W. C. F. Cochrane Database Syst. Rev. 2003, 7, 1.

[3] Fitzwater, D.; Macknin, M. Clin. Pediatr. 1992, 31, 308.

[4] Berkenwald, A.; Pires, J.; Ellsworth, P. J. Pediatr. Urol. 2016, 12, $220 . e 1$.

[5] Henrique, J. S.; Falcare, R. S.; Lopes, P. S. Pharmacia Brasileira. 2006, 56, 22.

[6] Barros, N. R.; Miranda, M. C. R.; Borges, F. A.; Mendonça, R. J.; Cilli, E. M.; Herculano, R. D. Int. J. Pept. Res. Ther. 2016, 22, 435.
[7] Mendonça, R. J.; Maurício, V. B.; Teixeira, L. B.; Lachat, J. J.; Coutinho-Netto, J. Phytother. Res. 2010, 24, 764.

[8] Mrué, F.; Coutinho-Netto, J.; Ceneviva, R.; Lachat, J. J.; Thomazine, J. A.; Tambelini, H. Mater. Res. 2004, 7, 277.

[9] Ereno, C.; Guimarães, S. A. C.; Pasetto, S.; Herculano, R. D.; Silva, C. P.; Graeff, C. F. O.; Tavano, O.; Baffa, O.; Kinoshita, A. Mater. Res. A. 2010, 95A, 932.

[10] Araujo, M. M.; Massuda, E. T.; Hyppolito, M. A. Acta Cir. Bras. 2012, 27, 566.

[11] Phaechamud, T.; Issarayungyuen, P.; Pichayakorn, W. Int. J. Biol. Macromol. 2016, 85, 634.

[12] Aielo, P. B.; Borges, F. A.; Romeira, K. M.; Miranda, M. C. R.; Arruda, L. B.; Lisboa-Filho, P. N.; Drago, B. C.; Herculano, R. D. Mater. Res. 2014, 17, 146.

[13] Pichayakorn, W.; Suksaeree, J.; Boonme, P.; Amnuaikit, T.; Taweepreda, W.; Ritthidej, G. J. Membr. Sci. 2012, 411, 81.

[14] Herculano, R. D.; Pereira, C. P.; Ereno, C.; Catanzaro-Guimarães, S. A.; Kinoshita, A.; Graeff, C. F. O. Mater. Res. 2009, 12, 253.

[15] Murbach, H. D.; Ogawa, G. J.; Borges, F. A.; Miranda, M. C. R.; Lopes, R.; Barros, N. R.; Mazalli, A. V. G.; Silvia, R. G.; Cinman, J. L. F.; Drago, B. C.; Herculano, R. D. Int. J. Biomater. 2014, 2014, 1.

[16] Miranda, M. C. R. Obtenção e estudos físico-químicos de biomembranas conjugadas de látex e peptídeos bioativos. M.Sc. Dissertation, Instituto de Química de Araraquara-UNESP, Araraquara, 2014.

[17] Akhgari, A.; Farahmanda, F.; Afrasiabi Garekani, H.; Sadeghi, F.; Vandamme, T. F. Eur. J. Pharm. Sci. 2006, 28, 307.

[18] Onuma, Y.; Satake, M.; Ukena, T.; Roux, J.; Chanteau, S.; Rasolofonirina, N.; Ratsimaloto, M.; Naoki, H.; Yasumoto, T. Toxicon 1999, 37, 55.

[19] Fischer, D.; Li, Y.; Ahlemeyer, B.; Krieglstein, J.; Kissel, T. Biomaterials 2003, 24, 1121.

[20] Blaabjerg, M. S. B.; Andersen, K. E.; Bindslev-Jensen, C.; Mortz, C. G. Contact Dermat. 2015, 73, 21.

[21] McMahan, C.; Kostya, D.; Lhamo, D. L.; Cornish, K. J. Appl. Polym. Sci. 2015, 132, 42051.

[22] Herculano, R. D.; Guimarães, S. A. C.; Belmonte, G. C.; Duarte, M. A. H.; Oliveira-Júnior, O. N.; Kinoshita, A.; Graeff, C. F. O. Mater. Res. 2010, 13, 57.

[23] Borges, F. A.; Bolognesi, L. F. C.; Trecco, A.; Drago, B. C.; Arruda, L. B.; Lisboa-Filho, P. N.; Pierri, E. G.; Graeff, C. F. O.; Santos, A. G.; Miranda, M. C. R.; Herculano, R. D. ISRN Polym. Sci. 2014, 2014, 1.

[24] Costa, P. J. C. Bras. Cienc. Farm. Rev. 2002, 38, 141.

[25] Steingräber, T.; Schtoltz, T.; Rodrigues, P. O. Rev. Colomb. Ciencias Quim. Farm. 2008, 37, 122.

[26] Borges, F. A.; Almeida-Filho, E.; Miranda, M. C. R.; dos Santos, M. L.; Herculano, R. D.; Guastaldi, A. C. J. Biomater. Sci. Polym. Ed. 2015, 26, 1256. 